\title{
Respuesta a las Consideraciones del autor Cassiani-Miranda al respecto de la Comportamiento psicométrico de la Zung Self- Rating Anxiety Scale-15 (SAS-15) versión español, durante el aislamiento físico por pandemia por COVID-19
}

\author{
Ulbaldo Enrique Rodríguez-De Avila (iD) ${ }^{1}$, Zuleima Lucía Leon-Valle (iD)², Guillermo Augusto Ceballos-Ospino (iD) ${ }^{3}$ \\ 1. Universidad del Magdalena. Santa Marta, Colombia. Correo: rodriguez.ubaldo@gmail.com - https://orcid.org/0000-0001-5907-001X \\ 2. Universidad del Magdalena. Santa Marta, Colombia. Correo electrónico: zuleimaleon@gmail.com - http://orcid.org/0000-0002-9834-3284 \\ 3. Universidad del Magdalena. Santa Marta, Colombia. Correo electrónico: guillermoceballos@gmail.com - http://orcid.org/0000-0002-1568-7058
}

Señor Editor:

El profesor Cassiani-Miranda habla de < Errores en el análisis factorial de escala de ansiedad de Zung en una muestra colombiana ${ }^{1}>$ de nuestra autoría ${ }^{2}$, con el objetivo <de contribuir a promover la discusión constructiva sobre la literatura publicada>.

El profesor Cassiani-Miranda fundamenta de entrada lo que él Ilama Crítica Constructiva bajo esta premisa, refiriéndose a nuestro estudio ${ }^{2}$ así:

iniciaron el proceso de adaptación de la SAS de 20 ítems sin considerar el estudio de De la Ossa et al que evaluó el desempeño psicométrico de 3 versiones de la escala en donde se informó un adecuado desempeño psicométrico de las versiones de 5 y 10 ítems que han sido utilizadas en otros estudios en Colombia ${ }^{3}$.

Este argumento se parece más al enojo del niño al que no le prestan atención a su juego de su predilección, o al de los fanáticos del futbol que desdeñan las ventajas de los otros clubes por el solo hecho que no son de su pasión. De entrada, el profesor Cassiani-Miranda parte de una premisa meramente subjetiva (Errores en el análisis factorial de escala de ansiedad de Zung en una muestra colombiana $^{1}$ ), la que merece todo el respeto de nuestra parte, pero la que consideramos no válida, puesto que no presenta ningún dato objetivo para sustentar su tesis central. ¿Será que cuando un investigador, estudiando aportes originales de un estudio concreto, no se basa en los estudios de otro autor reciente, significa que aquel autor desconoce los avances en su estudio?... ¿Porque un investigador no menciona ni se basa en un autor específico, significa que no conoce la temática? En lo concreto: ¿Basarse en la propuesta de Zung ${ }^{4}$ de 1971 sin mencionar los estudios de Ossa et $a l^{3}$ de 2009 significa error en el estudio o desconocimiento? Pensar así es una inferencia arbitraria, posicionamiento anticientífico y hasta orgullo academicista, si se reclama por esa mención. Más pretencioso es afirmar que a partir de un estudio modesto ${ }^{4}$, <el constructo "ansiedad" está claramente caracterizado y la estructura factorial de escala ha sido ampliamente estudiada por lo tanto el AFE no era pertinente> como afirma CassianiMiranda. Tanto aquél modesto estudio ${ }^{4}$ como el nuestro ${ }^{2}$, igualmente modesto, reportan Coeficiente Alpha de Crombach, KMO, etc. Si los datos de estos dos estudios concuerdan, aunque en direcciones diferentes, no será ésta una evidencia que el estudio de Zung ${ }^{4}$ tiene algo de interesante y, por tanto, ¿ंvale la pena seguir profundizando? Por otro lado, ¿será el constructo "ansiedad" una temática ya resuelta en su comprensión absoluta a partir de un estudio psicométrico de la predilección de CassianiMiranda?; respetaría a quien responda que sí, pero Yo en nada gastaría una letra en defender el NO, dado que la afirmación se cae por su propio peso. 
Para terminar, como la tesis de entrada de CassianiMiranda no es sustentada con datos objetivos, el resto de la argumentación del respetado profesor se torna una postura válida (subjetiva) para el estudio de metodología de la investigación, pero se encuentra fuera de foco para sustentar su tesis respecto de nuestro estudio.

\section{REFERENCIAS BIBLIOGRÁFICAS}

1. Cassiani-Miranda CA. Errores en el análisis factorial de escala de ansiedad de Zung en una muestra colombiana. Duazary. 2020; 17(4): 11 -3. Doi: https://doi.org/10.21676/2389783X.3701

2. Rodríguez-de Avila UE, Leon-Valle ZL, CeballosOspino GA. Comportamiento psicométrico de la Zung Self-Rating Anxiety Scale-15 (SAS-15) versión español, durante el aislamiento físico por pandemia por COVID-19. Duazary. 2020; 17(3): 7-9. Doi: https://doi.org/10.21676/2389783X.3469

3. De La Ossa Susana, Martinez Y, Herazo E, Campo A. Estudio de la consistencia interna y estructura factorial de tres versiones de la escala de Zung para ansiedad. Colombia Médica. 2009;40(1):71-7. Disponible en: http://www.scielo.org.co/pdf/cm/v40n1/v40n1a6. pdf

4. Zung W. A Rating Instrument For Anxiety Disorders. Psychosomatics. 1971; 12(6): 371-379. Doi: https://doi.org/10.1016/\$00333182(71)71479-013 